\title{
Multiple Scansions in Loanword Phonology: Evidence from Cantonese
}

\author{
Daniel silverman
}

UCLA

\section{INTRODUCTION}

In loanword phonology we seek to uncover the processes by which speakers possessing one phonological system perceive, apply native representational constraints on, and ultimately produce forms which have been generated by a different phonological system. In other words, loanwords do not come equipped with their own phonological representation. For any phonetic string, it is only native speakers for whom a fully articulated phonological structure is present. As host language speakers perceive foreign forms solely in accordance with their own phonological system, they instantiate native representations on the acoustic signal, fitting the superficial input into their own phonological system as closely as possible.

Given these assumptions, it should not be surprising that despite the identity of a given acoustic signal when impinging upon the inner ear of speakers of different languages, this input may be represented, and ultimately produced in a distinct manner in each language it enters.

The loanword phonology under investigation here, that of Cantonese, will be shown to possess two distinct levels. The first level of loanword phonology consists of a parsing of the input signal into unprosodized segment-sized chunks, for which native feature matrices are provided. As this level of loanword phonology is solely concerned with perceiving the input, and providing a preliminary linguistic representation, we may refer it as the Perceptual Level.

It is only when full prosodic structure is supplied for the incoming form that the raw segmental material may undergo phonological processes, so that it may be realized in conformity with native prosodic constraints on syllable structure. As this stage of the loanword phonology admits the possibility of true phonological processes acting on segments, it may be regarded as the Operative Level of the loanword phonology.

The processes which apply at the Operative Level of the Cantonese loanword phonology do not exist in native phonological derivations. As these operations were not acquired during the initial acquisition period, they exist in a separate domain from native phonological operations, presumably supplied by Universal Grammar. Their only property common with native phonological processes is that the same constraints exert an influence on the output of both systems.

I will provide evidence for the Perceptual Level and the operative Level of the loanword phonology by showing that loanwords undergo two distinct, ordered scansions during the 
course of the derivation. Scansion one will be shown to correspond to the Perceptual Level of the loanword phonology, providing raw segmental representation to incoming forms.

Scansion Two will be shown to correspond to the operative Level of the loanword phonology, providing prosodic representation which will be shown to trigger various phonological operations on the perceived segments.

1. CANTONESE PHONOTACTICS

The Cantonese segment inventory is shown in (1).

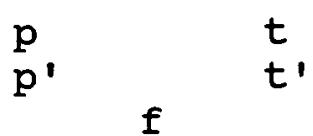

In n

1

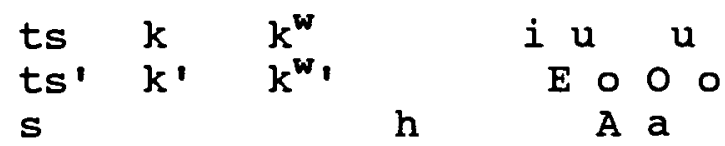

ng

Y w

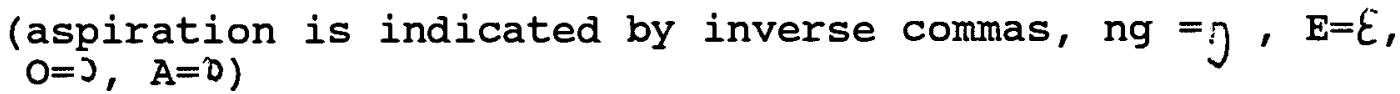

The superficial syllable in Cantonese is of the form (C) VX, allowing neither branching onsets nor branching codas. While any consonantal segment may serve as onset, only those listed in (2) may serve as coda.

$\begin{array}{lll}\mathrm{p} & \mathrm{t} & \mathrm{k} \\ \mathrm{m} & \mathrm{n} & \mathrm{ng} \\ \mathrm{w} & \mathrm{y} & \end{array}$

I will assume that Cantonese syllables are obligatorily bimoraic (Duanmu 1990), as all syllables possess either codas or long vowels. One of seven tones is lexically associated with every syllable, displayed in (3).

$$
\begin{array}{llll}
55 & ([\mathrm{H}]) & 53 & ([\mathrm{HM}]) \\
33 & ([\mathrm{M}]) & 35 & ([\mathrm{MH}]) \\
22 & ([\mathrm{~L}]) & 24 & ([\mathrm{LM}]) \\
21 & & &
\end{array}
$$

Tones are presented with traditional notation. However, the parenthesized notation will be employed throughout this paper, as it is more consistent with recent tonological theory. The lexical contour tones will play an extremely limited role in the present discussion, acting only to constrain the form superficial contours may take. The only tonemes which play an active role in the present analysis are $[\mathrm{L}],[\mathrm{M}]$, and $[\mathrm{H}]$. I represent tone solely in terms of its phonetic realization. No theoretical claims regarding the representation of tone are intended by this notation. 


\section{THE ANALYSIS OF PITCH CONTRASTS: STRESS-TO-TONE}

Stress languages tend to possess a loose correlation between the degree of stressing and pitch height, as determined by $F_{0}$ of the vocalic elements of the speech signal. For example, in English, syllables receiving primary stress tend to be higher in pitch than other syllables. The phonetic phenomenon of pitch contrast is lexical in tonal languages such as cantonese. As Cantonese speakers do not have access to English phonological representation, English phonetic pitch patterns will be perceived at the Perceptual Level as phonological tonal patterns. Therefore, English syllables receiving primary stress are perceived as possessing $[\mathrm{H}$ ] tones, whereas other syllables are perceived as possessing [M] tones. In (4) are some examples. (Data is primarily from Zhang 1986.)

$\begin{array}{llll}\text { (4) a. } & \text { card } & \rightarrow & {[\operatorname{kat}[\mathrm{H}]]} \\ & \text { gin } & \rightarrow & {[\operatorname{tsin}[\mathrm{H}]]} \\ \text { b. } & \text { cigar } & \rightarrow & {[\operatorname{syt}[\mathrm{M}] \mathrm{ka}[\mathrm{H}]]} \\ & \text { guitar } & \rightarrow & {[\operatorname{kit}[\mathrm{M}] \mathrm{t} \cdot \mathrm{a}[\mathrm{H}]]}\end{array}$

A further tonal process applies to forms that undergo epenthesis due to Cantonese syllable structure constraints (SSCs). While English permits both branching onsets and branching codas, the Cantonese syllable is of the form (C) VX. epenthesis sometimes applies to break up a consonant cluster. such forms are supplied with a low [L]. tone. Examples are in (5), and some hypothesized derivations are in (6).

(5)

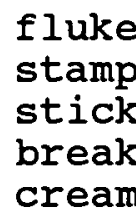

(6) input:

Perceptual Level: Operative Level: surface:

$$
\begin{aligned}
& \rightarrow \quad[f u[L] \operatorname{luk}[\mathrm{H}]] \\
& \rightarrow \quad[\mathrm{si}[\mathrm{L}] \operatorname{tam}[\mathrm{H}]] \\
& \rightarrow \quad[\mathrm{si}[\mathrm{L}] \operatorname{tik}[\mathrm{H}]] \\
& \rightarrow \quad \text { [pik[L] lik[H]] } \\
& \rightarrow \quad[\operatorname{kei}[\mathrm{L}] \lim [\mathrm{H}]]
\end{aligned}
$$

Within the loanword vocabulary, all final syllables that are not perceived as possessing a $[\mathrm{H}]$ tone surface with a pitch rise, as exemplified in (7).

$$
\begin{array}{llll}
\text { (a) body } & \rightarrow & {[\mathrm{po}[\mathrm{H}] \mathrm{ti}[\mathrm{MH}]]} \\
\text { (b) cello } & \rightarrow & {\left[\mathrm{ts} \mathrm{I}^{\prime}[\mathrm{H}] \mathrm{lou}[\mathrm{MH}]\right]} \\
\text { (c) fashion } & \rightarrow & {[\mathrm{fa}[\mathrm{H}] \text { son }[\mathrm{MH}]]}
\end{array}
$$

Extending the autosegmental analysis first presented in Yip (1980), I assume that a high $[\mathrm{H}]$ boundary tone attaches formfinally at some stage in the operative loanword phonology. This offers the clearest explanation why almost all words end with a $[\mathrm{H}]$ tone. This also explains why, for example, the tone realized 
on derived syllables is superficially different word-internally versus word-finally, as exemplified in (8).

$$
\begin{aligned}
& \text { a. buffet } \rightarrow \text { [pou[M] fei[H]] } \\
& \text { cigar } \rightarrow \text { [syt }[\mathrm{M}] \mathrm{ka}[\mathrm{H}]] \\
& \text { b. motor } \rightarrow[\mathrm{mo}[\mathrm{H}] \text { ta }[\mathrm{MH}]] \\
& \text { soda } \rightarrow[\mathrm{sO}[\mathrm{H}] \text { ta }[\mathrm{MH}]] \\
& \text { c. stick } \rightarrow \text { [si[L] tik[H]] } \\
& \text { fluke } \rightarrow \text { [fu[L] luk [H]] } \\
& \text { d. lace } \rightarrow \text { [lei[H] si[MH]] } \\
& \text { film } \rightarrow \text { [fei[H] lAm [MH]] }
\end{aligned}
$$

I will assume along with whitaker $(1955 / 56)$ that this tone possesses independent morphemic status, indicating a state of intimacy and/or familiarity between the speaker and the person/object in question.

Finally, note that tonal suffixation applies after prosodization. This explains why form-final epenthesized vowels possess the pitch rise, as shown in (9).

$$
\text { bus } \rightarrow[\mathrm{pa}[\mathrm{H}] \mathrm{si}[\mathrm{MH}]] \text { (*pa[H] si[L]]). }
$$

Evidence from the tonal pattern of English free root compounds indicates that the domain of pitch contrast analysis - henceforth the PCA domain -- is the English free morpheme.

\section{(10) PCA domain:}

$$
\text { <English free morpheme> }
$$

In the data in (11), despite superficial pitch contrasts, tone is perceived solely within the PCA domain. This indicates that Cantonese speakers' explicit knowledge of English morphology exerts an influence on their analysis. So, for example, both syllables in the English compound [dockyard], despite superficial pitch contrasts, are realized in cantonese with [H] tones. The forms in (11b) indicate that Cantonese speakers' imperfect knowledge of English morphology is sometimes manifested in their treatment of loans, in that "-phone" compounds are treated as free-root compounds.

$$
\begin{array}{llll}
\text { (11) a. } & \begin{array}{l}
\text { dockyard } \\
\text { floorshow }
\end{array} & \rightarrow & {[\operatorname{tok}[\mathrm{H}] \mathrm{ja}[\mathrm{H}]]} \\
\text { sideboard } & \rightarrow & {[\mathrm{fO}[\mathrm{H}] \operatorname{sou}[\mathrm{H}]]} \\
\text { saxophone } & \rightarrow & {[\operatorname{sik}[\mathrm{H}] \operatorname{put}[\mathrm{H}]]} \\
\text { dictaphone } & \rightarrow & {[\operatorname{tik}[\mathrm{H}] \text { ta }[\mathrm{M}] \text { fung }[\mathrm{H}]]}
\end{array}
$$

3. CONSTRAINTS AT THE PERCEPTUAL LEVEL

We will now consider aspects of the hypothesized Perceptual Level of the loanword phonology.

As English words enter Cantonese, Cantonese speakers parse the acoustic signal into segment-sized chunks, instantiating native feature matrices which best capture the articulatory and/or acoustic quality of the input, constrained in their analysis of the incoming acoustic signal by their own 
phonological system.

When Cantonese possesses a particular contrast in its native segment inventory, it possesses the necessary tools to provide an accurate featural representation for segment-sized chunks of the input signal which contrast similarly. I assume that Cantonese speakers perceive each and every parsed element of the input, constrained only by their segment inventory. There is, prima facie, no principled reason to assume that a segment which is perceptible in one position within the input signal should be perceived distinctly in another position. Therefore, at the Perceptual Level, native segments will be provided irrespective of syllable structure constraints that hold on Cantonese surface forms. We may refer to this notion as the Perceptual Uniformity Hypothesis.

(12) Perceptual Uniformity Hypothesis:

At the Perceptual Level, acoustically identical input is uniformly provided with identical feature matrices

It should be noted that the Perceptual Uniformity Hypothesis makes no reference to allophonic rules acting within the lending language. Thus, for example, English dark /1/, which surfaces syllable-finally, is obviously not acoustically identical to coronal $/ 1 /$, which surfaces elsewhere. Therefore, host language speakers will indeed perceive such segments as acoustically distinct, potentially providing them with distinct representations:

$$
\begin{array}{lll}
\text { a. lift } & \rightarrow & {[\text { lip] }} \\
\text { lorry } & \rightarrow & {[10 \text { lei] }} \\
\text { file } & \rightarrow & {[\text { fai lou }} \\
\text { coil } & \rightarrow & {[k \text { 'oi lou }]}
\end{array}
$$

In (13a) coronal $/ 1 /$ is fully incorporated into cantonese. Dark $/ 1 /$, however, is treated in a distinct manner, its backness apparently manifested by /o/ epenthesis.

To exemplify Perceptual Level processes, voicing is never contrastive in Cantonese; stops are usually realized voiceless. Thus, as English forms enter Cantonese, both voiced and unaspirated voiceless obstruents are perceived identically, as the native Cantonese phonological system does not possess the proper feature matrices to accommodate this constrast. Some examples are given in (14).

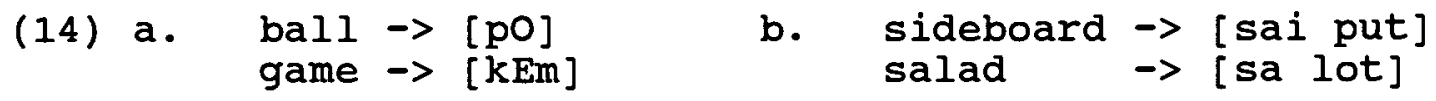

In (14a) onsets are realized voiceless, and in (14b) formfinal codas are realized voiceless.

English onset $/ r /$ is always perceived as $/ 1 /$ in Cantonese. Again, the perception of this chunk of the acoustic signal is constrained by the Cantonese segment inventory. As Cantonese 
lacks /r/, speakers are only equipped to represent, and ultimately produce the native feature matrix which most closely approximates this segment, namely /l/.

$$
\begin{array}{llll}
\text { a. bearing } & \rightarrow & {[\mathrm{pE} \text { ling }]} \\
\text { b. warrant } & \rightarrow & {[\text { wO loen }]} \\
\text { c. lorry } & \rightarrow & {[10 \text { lei }]}
\end{array}
$$

(15) shows that pre-vocalic English / $/$ is perceived as /l/ by Cantonese speakers.

English possesses a contrast between /s/ and /sh/. Cantonese, on the other hand, does not possess the voiceless palato-alveolar fricative. As Cantonese speakers are thus illequipped to fully accommodate English / sh/, they represent the segment as /s/, which is the cantonese segment closest in phonetic quality to the input:

$$
\begin{array}{lll}
\text { [show] } & \rightarrow & \text { [sou ] } \\
\text { [sharp] } & \rightarrow & \text { [sap] } \\
\text { [shaft] } & \rightarrow & \text { [sAp] }
\end{array}
$$

(16) shows that English /sh/ is perceived as /s/ in Cantonese.

Aspiration is predictable in English, and therefore not underlyingly specified. In English strict onset position, voiceless plosive onsets acquire aspiration. As English forms enter Cantonese, operations proceed on surface feature matrices, not on underlying representations. As Cantonese possesses an underlying aspiration distinction, speakers are capable of perceiving an aspiration distinction that English speakers may be unaware of. They therefore (usually) supply the appropriate feature matrix from their native segment inventory, thus realizing the aspirated/unaspirated contrast.

$$
\begin{array}{llll}
\text { pie } & \rightarrow\left[p^{\prime} a i\right] & \text { bumper } & \rightarrow \text { [pAm pa] } \\
\text { tie } & >\text { [t'ai] } & \text { motor } & \rightarrow \text { [mo ta] } \\
\text { cut } & >\text { [k'At] } & \text { chocolate } & \rightarrow \text { [tsy ku lik] }
\end{array}
$$

In (17), English aspirated voiceless plosives are perceived as such by Cantonese speakers. English unaspirated voiceless plosives are also fully accommodated.

Cantonese lacks the voiced labio-dental fricative /v/. Therefore, when encountering this segment, Cantonese speakers represent, and subsequently produce the native segment which most closely approximates /v/'s acoustic properties: /w/.

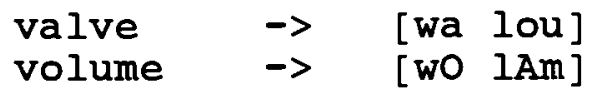

(18) shows English /v/ being realized as /w/ in Cantonese.

4. CONSTRAINTS AT THE OPERATIVE LEVEL: RULES TRIGGERED BY PROSODIZATION 
The phoneme inventories of Cantonese and English may both possess a particular segment, but due to the more constrained structure of the Cantonese syllable, certain operations must apply as the English input is provided with Cantonese prosodic structure. It is only when full syllabification is provided -at the Operative Level of the loanword phonology -- that native sscs will trigger phonological operations. It is at this point in the derivation of a loanword where the Perceptual uniformity Hypothesis ceases exerting a force on the derivation.

To exemplify operative Level operations, while both

English and Cantonese possess fricatives and affricates in their phoneme inventories, only in English may these surface in both onset and coda position. In Cantonese they may only serve as onsets. I assume that the output of the Perceptual Level, before prosodic structure is provided, Cantonese speakers indeed represent English fricatives and affricates as such. It is only at the operative Level, when full syllabification is provided, and sscs consequently hold, that a phonological process of occlusivization will apply to fricatives and affricates that have been assigned to coda positions in cantonese. The rule may be stated as in (19), and examples are in (20). (21) shows an abbreviated derivation of the Cantonese forms for English shaft and lift.

$$
\begin{aligned}
& c \rightarrow[- \text { cont }] /[]_{s} \\
& \begin{array}{llllll}
\text { film } & \rightarrow & {[\text { fei lAm }]} & \text { shaft } & \rightarrow & {[\text { sAp] }} \\
\text { floorshow } \rightarrow & {[\text { fo sou }]} & \text { lift } & \rightarrow & {[\text { lip] }}
\end{array} \\
& \text { 1. input: } \\
& \text { shaft } \\
& \text { lift } \\
& \text { 2. Perceptual Level: [<saft>] } \\
& {[<\text { ift }>]} \\
& \text { s } \\
& \text { 111 } \\
& \text { 3. Operative Level: [SAp] } \\
& \text { S }
\end{aligned}
$$

At the Perceptual Level, a segment-by-segment representation is provided. As cantonese lacks the voiceless palato-alveolar fricative, English /sh/ is perceived as the native feature bundle which most closely approximates it: /s/. At the operative Level, full syllable structure is supplied for the form, and SSCs consequently trigger phonological processes: codas are rendered non-branching, and /f/ occlusivizes to /p/, as fricatives are not permissible codas in Cantonese.

We have already noted the fact that Cantonese disallows released stops in coda position. While form-final unreleased stops are in free variation with released stops in English, Cantonese forms do not reflect this contrast. Given the Perceptual Uniformity Hypothesis, I assume that the output of the Perceptual Level may contain released stops wherever in the segmental string they arise, as such segments exist in Cantonese, and therefore may be perceived by Cantonese speakers, presumably as aspiration. However, at the operative Level, as full prosodic structure is provided and SSCs apply, a phonological process 
results in the loss of aspiration in segments surfacing in coda position. Universal Grammar presumably supplies a rule of the form in (22). Examples are in (23), and derivations are in (24).

$$
\begin{aligned}
& \text { C } \rightarrow[-s \cdot g \cdot] /[]_{s} \\
& \text { salad(') } \rightarrow \text { [sa lot }] \quad \text { card } \rightarrow \text { [k'at(')] } \\
& \text { input: salad card } \\
& \text { Perceptual Level: [<sa lot(') }\rangle] \quad\left[\left\langle\mathrm{k}^{\prime} \text { at (') }\right\rangle\right] \\
& \text { Operative Level: [sa lot] [k'at] }
\end{aligned}
$$

The derivation in (24) shows that aspiration may be perceived anywhere in the string at the Perceptual Level of the loanword phonology. However, at the Operative Level, when full prosodic structure is supplied and SSCs hold, a rule of syllablefinal de-aspiration applies.

All /s/s (and segments perceived as /s/, i.e., /sh/) occurring pre-consonantally or word-finally, are treated in identical fashion: the segment is retained by epenthesizing a vowel to its right. This process is exemplified in (25). Abbreviated derivations are shown in (26).

(25)

(26)

$\begin{array}{lll}\text { a. tips } & -> & {[t i p \text { si] }} \\ \text { waste } & -> & {[w 0 i \text { si }]} \\ \text { stamp } & -> & {[s i \text { tam }]} \\ \text { store } & \rightarrow & {[s i \text { to }]}\end{array}$

input: Perceptual Level: [<tips $]$ Operative Level:

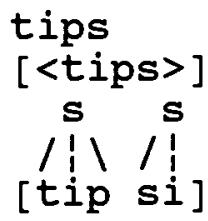

store

$[<$ sto $]$

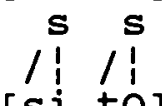

[si to

5. EVIDENCE FOR LEVEL-ORDERED LOANWORD PHONOLOGY: THE ANALYSIS OF TRUNCATED FORMS

In this section, I present evidence from truncated English loanwords in cantonese which clearly supports the existence of two ordered levels of the loanword phonology.

In at least one lexical class -- university subjects -- not all the syllables in English forms are superficially realized in Cantonese. Normally, these truncated forms consist of the first two syllables of the full form, as shown in (27).

(27) a. economics

b. biology insurance

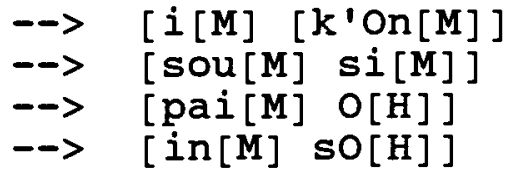

$\rightarrow \quad\left[i[M] \quad\left[k^{\prime}\right.\right.$ On $\left.[M]\right]$

$\rightarrow \quad[\operatorname{pai}[\mathrm{M}] \quad \mathrm{O}[\mathrm{H}]]$

$\rightarrow \quad[$ in $[M]$ so $[\mathrm{H}]]$

In (27a), the PCA domain remains the full English form, 
despite the fact that only a portion of the form is realized in cantonese. The pitches of the surviving syllables are contrasted not solely with each other, but with those of the full English form. To exemplify, the tones in the truncated form $\left[i[M] k^{\prime}\right.$ On $\left.[M]\right]$ are realized as if tone had been assigned to every syllable in the full English form ([economics]). And so, despite the fact that a pitch contrast exists in the surviving English syllables, this contrast is neutralized. This neutralization is motivated by the fact that subtle pitch contrasts cannot always be accommodated by the limited set of tone options that cantonese possesses.

The natural science cluster displays a slightly different pattern, shown in (28).

\section{(28) physics chemistry biology $\rightarrow$ [fi[H] k'Em[H] pai[M]]}

Each element is assigned tone in relation to its full underlying form. We therefore posit the derivation in (30). As I am now arguing that there are phonologically isolable correlates to the hypothesized Perceptual and operative Levels of the loanword phonology, I will henceforth employ the term Scansion one when referring to the Perceptual Level, Scansion Two when referring to the Operative Level.

(29) Scansion One $=$ Perceptual Level
Scansion Two $=$ Operative Level

(30)

input: physics chemistry biology

Scansion One: ? $[<\mathrm{fi}[\mathrm{H}] \mathrm{sik}[\mathrm{M}] \mathrm{s}>$ $<k^{\prime} \mathrm{E}[\mathrm{H}] \mathrm{mi}[\mathrm{M}]$ s tli[M]> $<\operatorname{pai}[\mathrm{M}] \mathrm{O}[\mathrm{H}] \mathrm{IO}[\mathrm{M}] \mathrm{tsi}[\mathrm{M}]>]$

Scansion Two: $\left[\mathrm{fi}[\mathrm{H}] \mathrm{k}^{\prime} \operatorname{Em}[\mathrm{H}] \mathrm{pai}[\mathrm{M}]\right]$ surface: $[\mathrm{fi}[\mathrm{H}] \mathrm{k} ' \operatorname{Em}[\mathrm{H}] \operatorname{pai}[\mathrm{M}]]$

There is evidence beyond stress-to-tone perception supporting this analysis. Observe that, unlike most other forms, those in (27a) do not have the high [H] tone suffix attached word-finally (i.e., we do not observe the form *[i[H] $k^{\prime}$ On [MH]] or perhaps *[i[M] $k^{\prime}$ On $\left.\left.[\mathrm{MH}]\right]\right)$. Since the tonal suffix fails to surface in these forms, I assume that within the loanword phonology -- on scansion Two -- the boundary tone indeed attaches, but when the form is truncated, the tone is deleted with the segmental material. Thus the [H] tone suffix attaches earlier in the derivation than the deletion of material from the surface representation. Were the high tone attached very late in the derivation, it would be expected to surface in the forms in (27a).

It is apparent then, that as English forms enter Cantonese, they are preliminarily scanned in their entirety. Then, in at least one lexical class, syllables beyond an initial left-toright binary foot may be deleted. Syllable deletion crucially follows the establishment of a PCA domain. In other words, the Perceptual Level of the loanword phonology is manifested as a 
preliminary scansion across the entire form. It is only after this preliminary scansion that the operative Level phonology is reached.

In fact, there are certain truncated forms whose tonal patterns indicate that the PCA domain for such forms is not based on the full English form, but is instead based on the truncated form:

$$
\begin{array}{lll}
\text { composition } & \rightarrow & {\left[\mathrm{k}^{\prime} \mathrm{Om}[\mathrm{H}] \mathrm{p}^{\prime} \mathrm{ou}[\mathrm{MH}]\right]} \\
\text { geography } & \rightarrow & {[\mathrm{tsOk}[\mathrm{H}] \mathrm{ka}[\mathrm{MH}]]} \\
\text { marketing } & \rightarrow & {\left[\mathrm{ma}[\mathrm{H}] \mathrm{k}^{\prime} \mathrm{Et}[\mathrm{MH}]\right]}
\end{array}
$$

In these data, it is apparent that truncation precedes scansion Two. Two independent lines of evidence support this analysis.

First, the PCA domain is the truncated form, not the full underlying form. Cantonese speakers are perceiving these relative pitch contrasts with respect to the syllables present on the surface.

The second line of evidence indicating that truncation precedes further prosodic analysis in these forms stems from the behavior of the boundary tone. Note that the boundary tone is present in these forms. Unlike the data in (27a), the boundary tone is not deleted along with segmental material. This indicates that it attaches after truncation.

Cantonese speakers apparently may apply truncation at the earliest stages of the derivation, i.e., upon reception of the acoustic input on scansion one. As pitch is perceived solely in relation to those pitches present in the representation, the tonal patterns in (31) can be accounted for only if we assume that Cantonese speakers are attending only to the first two perceived pitches of the acoustic input.

We have been assuming that Scansion one provides melodic representation, and melodic representation only, for the incoming acoustic signal. However, I have just presented evidence that truncation may apply as scansion one proceeds. Therefore, it must be the case that a certain amount of prosodic structure, namely, a binary foot, syllable nodes and moras, are supplied immediately upon reception of the acoustic signal. This is the only way in which Cantonese speakers are capable of applying truncation so that exactly two syllables are salvaged as scansion one tone perception proceeds (cf. McCarthy and Prince (1986) for a discussion of truncation and prosodic templates).

Alternatively, truncation may apply on Scansion Two. This strategy accounts for forms like economics $\rightarrow$ [i[M] k'On[M]], which have obviously undergone both Scansion one and Scansion Two processes before truncation applies.

The two strategies are schematized in (32). 
1. incoming acoustic signal

1. incoming acoustic signal

2. Scansion One/truncation

2. Scansion one

3. Scansion Two

4. Stray Erasure

3. Scansion Two/truncation

4. Stray Erasure

5. surface

5. surface

(32) displays the two truncation strategies that cantonese loanword phonology employs. Truncation may apply either during Scansion one (Truncation Strategy (A)), or during Scansion Two (Truncation Strategy (B)). At the end of the derivation, unlicensed material deletes through stray Erasure. These two derivations account for both truncation paradigms, exemplified in (27a) and (31).

Cantonese speakers seemingly employ either of these strategies on an optional basis (though this optionality holds only between forms, and not within them).

6. FURTHER EVIDENCE FOR MULTIPLE SCANSIONS: THE TREATMENT OF C-LIQUID CLUSTERS

We will now consider further data which support the hypothesis that syllable nodes and a binary foot are provided on Scansion one, and further, that prosodic constraints act on the output of the Perceptual Level (Scansion One), triggering phonological processes at the operative Level (Scansion Two). English liquids sometimes delete when occurring in a consonant cluster. Elsewhere, they are salvaged by epenthesis:

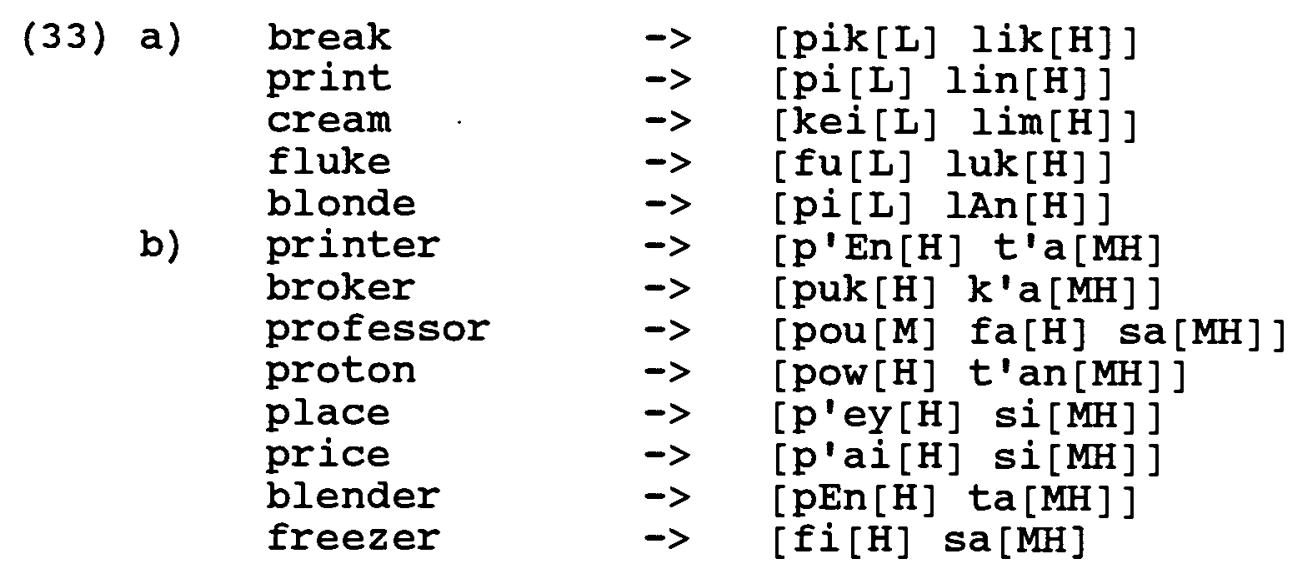

We observe liquid deletion in polysyllabic English forms. otherwise, in monosyllabic English forms, the liquid is preserved, and a vowel is epenthesized. These data suggest that the binary foot exerts an influence in cantonese in that a segment which normally undergoes deletion in loanwords is preserved in one instance: just in case the resulting form is bisyllabic, i.e., consists of one binary foot. (The form brandy $\rightarrow$ [pAt[2] lan[5] tei[35]] is uninteresting for the present analysis, as its pronunciation is based on the characters employed in the Mandarin English loanword. The only true 
exception of which I am aware is clutch $\rightarrow$ [kik lik tsi], in which the liquid is retained despite the fact that the output exceeds bisyllabicity.)

Note that the decision to delete or retain the liquid cannot be made until syllables have been constructed across the entire form. After it is determined that, for example, break is monosyllabic, epenthesis applies to break the cluster, resulting in a bisyllabic form. The algorithm employed is apparently:

(34) C-Liquid cluster strategies:

monosyllabic on Scansion one: epenthesis polysyllabic on Scansion one: deletion

Therefore, syllable nodes must be provided on Scansion one so that the correct prosodization strategy is applied.

The behavior of C-liquid clusters thus provides further evidence for multiple scansions, and for syllable node and binary foot provision on Scansion One. As Scansion one proceeds, syllable nodes are provided for elements perceived as possessing syllabicity, and a binary foot template is provided, attaching to the first two syllable nodes. Subsequent to scansion one, after a full syllable count has been made, the appropriate prosodization strategy is employed for c-liquid clusters. If the output of scansion one is monosyllabic, the liquid is salvaged, and $a$ vowel is epenthesized to fill the binary foot template. If the output of scansion one is polysyllabic, the liquid deletes, as the template has already been filled.

observe further that, for example, the near-minimal pair [p'i lin]/[[p'En ta] (from print/printer) confirm that segments perceived at the Perceptual Level (Scansion one) may undergo phonological rules -- in this case, deletion -- as prosodic structure is supplied at the operative Level (Scansion Two).

The Cantonese form for floorshow ([fO[H] sou[H]]) possesses some interesting properties. We have already seen that the tonal pattern for this form shows that it is composed of two PCA domains, indicating that Scansion one applies independently to each free morpheme encountered. Yet although floor is treated independently for the purpose of pitch contrast analysis, it is not treated independently by further aspects of the prosodic analysis. Specifically, we do not witness liquid retention and epenthesis to derive a bisyllabic form. Instead, as the full form (floorshow) is already bisyllabic, the liquid deletes, and floor surfaces as a monosyllable.

We have now provided evidence both from Truncation strategy (A), and from C-liquid prosodization strategies, that the Perceptual Level of the loanword phonology includes the perception of syllabicity, and provides a binary foot template for the incoming form. I propose that on Scansion one, syllable nodes are provided for the most salient components of the phonetic input: vocalic sonority peaks, as well as phonetically salient consonants which are otherwise unsyllabifiable. For example, post-vocalic/s/'s salience is most likely due to both its duration and its sibilance. When this segment is perceived 
post-vocalically, and is either pre-consonantal or form-final, it is perceived syllabically by Cantonese speakers, and hence provided with syllable nodes on Scansion one. In (35) are some derivations.

(35)

input:

Scansion one:
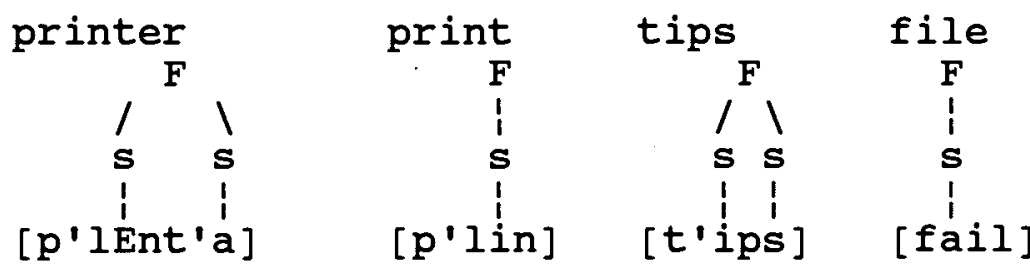

Scansion Two:
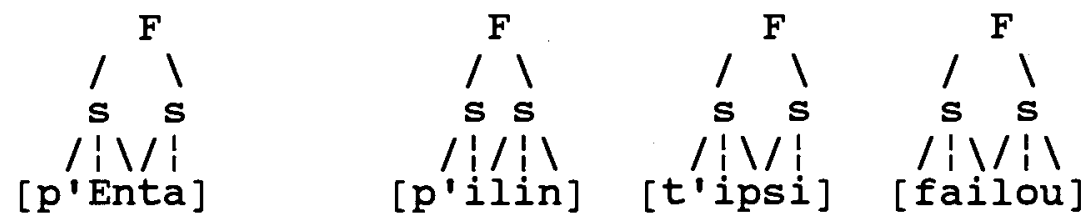

On Scansion One, feature matrices are provided, as well as syllable nodes for sonority peaks and phonetically salient segments that are otherwise unsyllabifiable. A binary foot template is provided, seeking to associate with syllable nodes. As Scansion Two proceeds, prosodization strategies apply, constrained by the template. Now, the perceived liquid in printer is deleted, while the liquids in print and file are salvaged through epenthesizing a vowel. Thus the output is bisyllabic in either case, satisfying the template. tips is perceived as possessing two syllables, and is consequently prosodized as such on Scansion Two.

Note that unsyllabifiable /s/ and /l/ exhibit distinct behavior in the following way: /s/ is always perceived syllabically, and is thus always retained and salvaged by epenthesis. $/ 1 /$, on the other hand, triggers epenthesis conditionally: only if the resulting output will fill the binary foot template.

We may therefore conclude that /s/ acquires a syllable node on Scansion one. $/ 1 /$, however, is never perceived as syllabic, but may trigger the construction of a syllable node on scansion Two. The decision relies crucially on the post-Scansion one syllable count. The presumed derivations are schematized in (36).

\begin{tabular}{|c|c|c|c|}
\hline Scansion One: & $\begin{array}{l}F \\
\text { I } \\
\text { ss } \\
11 \\
\text { Vs }\end{array}$ & 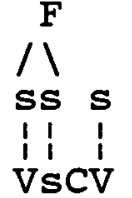 & $\begin{array}{r}\mathbf{F} \\
\mathbf{S} \\
\mathbf{5} \\
\mathrm{I} \\
\mathrm{ClV}\end{array}$ \\
\hline
\end{tabular}




$\begin{array}{rlllll}\text { Scansion Two: } & F & F & F & F \\ & / I & / & / & / \\ \text { ss } & \text { ss s } & \text { s s } & \text { s s } \\ \text { II } & \text { II I } & 1 & 1 & 1 \\ & \text { Vs } & \text { VscV } & \text { cVIV } & \text { cVCV }\end{array}$

In (36a), both $\mathrm{V}$ and /s/ are perceived syllabically. As the template is filled, no relevant template-triggered operations apply on Scansion Two. In (36b), three syllabic segments are perceived on Scansion one. Assuming truncation does not apply, the form will surface as trisyllabic. In (36c), a single syllabic element is perceived during scansion one. Now, the liquid may be salvaged by epenthesizing a vowel, thus filling the template. In (36d), two syllabic segments are perceived on Scansion one. As the template has already been filled, the liquid deletes.

\section{CONCLUSION}

I have now provided evidence that Cantonese loanword phonology possesses two distinct ordered levels. I have employed empirical evidence in conjunction with the Perceptual Uniformity Hypothesis to support my claim that the initial level of the loanword phonology consists of a parsing of the non-linguistic acoustic input into unprosodized segment-sized chunks, for which native feature matrices are provided. This level of representation has been termed the Perceptual Level of the loanword phonology, as it is concerned solely with providing a preliminary "raw" segmental representation for incoming forms.

The second level of the loanword phonology applies to the output of the Perceptual Level. During this stage, loanwords undergo prosodization, and thus native constraints on prosodic structure subsequently hold. I have provided evidence from segmental phenomena, in conjunction with the Perceptual Uniformity Hypothesis, arguing for this operative Level of the loanword phonology. Furthermore, as the rules employed at this level are peculiar to the Cantonese loanword phonology, and, crucially, do not exist in the native phonology, they are presumably available through Universal Grammar.

The analysis of truncated forms has provided strong supporting evidence for the present theory of loanword phonology, enabling us to phonologically isolate the Perceptual and operative Levels as a series of ordered scansions which forms undergo. Scansion one has been shown to correspond to the Perceptual Level, while scansion Two has been shown to correspond to the operative Level.

\section{Selected References}

Bauer, R. (1985) The Expanding Syllabary of Hong Kong Cantonese. C.L.A.O. vol.XIV.1: 99-111.

Duanmu, S. (1990) A Formal study of syllable, Tone, stress and Domain in Chinese Languages. Ph.D. dissertation, MIT. McCarthy, J.J., and A.S. Prince (1986) Prosodic Morphology. 
ms., UM Amherst, Brandeis U.

Whitaker, K.P.K. (1955/6) A study on the Modified Tones in Spoken Cantonese. Asia Major 5.1,5.2, 9-36, 184-207. Yip, M. (1980) The Tonal Phonology of Chinese. Ph.D. dissertation, MIT.

Zhang, R.S. 1986. Xianggang Guangzhouhua yingyu yinyi jieci de shengdiao guilu (Tonal Rules for English Loanwords in Hong Kong Cantonese). Zhongguo Yuwen (Chinese Language) $42-50$.

Dan Silverman

Department of Linguistics

$U C L A$

Los Angeles, CA 90024

izzys80@uclamvs.bitnet 